\title{
Diversity within the entomopathogenic fungal species Metarhizium flavoviride associated with agricultural crops in Denmark
}

Chad A. Keyser, Henrik H. De Fine Licht, Bernhardt M. Steinwender and Nicolai V. Meyling ${ }^{*}$

\begin{abstract}
Background: Knowledge of the natural occurrence and community structure of entomopathogenic fungi is important to understand their ecological role. Species of the genus Metarhizium are widespread in soils and have recently been reported to associate with plant roots, but the species M. flavoviride has so far received little attention and intra-specific diversity among isolate collections has never been assessed. In the present study M. flavoviride was found to be abundant among Metarhizium spp. isolates obtained from roots and root-associated soil of winter wheat, winter oilseed rape and neighboring uncultivated pastures at three geographically separated locations in Denmark. The objective was therefore to evaluate molecular diversity and resolve the potential population structure of $\mathrm{M}$. flavoviride.
\end{abstract}

Results: Of the 132 Metarhizium isolates obtained, morphological data and DNA sequencing revealed that 118 belonged to M. flavoviride, 13 to M. brunneum and one to M. majus. Further characterization of intraspecific variability within $M$. flavoviride was done by using amplified fragment length polymorphisms (AFLP) to evaluate diversity and potential crop and/or locality associations. A high level of diversity among the $M$. flavoviride isolates was observed, indicating that the isolates were not of the same clonal origin, and that certain haplotypes were shared with M. flavoviride isolates from other countries. However, no population structure in the form of significant haplotype groupings or habitat associations could be determined among the 118 analyzed M. flavoviride isolates.

Conclusions: This study represents the first in-depth analysis of the molecular diversity within a large isolate collection of the species M. flavoviride. The AFLP analysis confirmed a high level of intra-specific diversity within the species and lack of apparent association patterns with crop or location indicates limited ecological specialization. The relatively infrequent isolation of M. flavoviride directly from crop roots suggests low dependence of root association for the species.

Keywords: AFLP, Entomopathogenic fungi, Soil baiting, Rhizosphere competence, Population ecology

\section{Background}

The predominantly entomopathogenic fungal genus Metarhizium (Hypocreales: Clavicipitaceae) has a global distribution [1-3] and several species have been intensely researched for their pest control potential. Discordantly, limited focus has been given to the assessment of natural occurrence and distribution of this widespread fungal genus. Knowledge of the compositions of entomopathogenic fungal communities and

\footnotetext{
* Correspondence: nvm@plen.ku.dk

Department of Plant and Environmental Sciences, University of Copenhagen, Thorvaldsensvej 40, 1871 Frederiksberg, Denmark
}

structure of their populations is important to understand their ecological function and contribution to host regulation and potential for conservation biological control [4].

Evaluation of fungal diversity and community structure depends heavily on criteria for species identification. With few morphological distinct features, species referred to as $M$. anisopliae and variants thereof in the literature could belong to several different species if no explicit molecularly based identification has been conducted. A revised taxonomy of the $M$. anisopliae lineage based on a multigene phylogeny resolved nine species within what could 
be considered M. anisopliae sensu lato if based solely on morphology [5]. Recently, the taxonomy of the whole genus Metarhizium was revised leading to the inclusion of other genera as well as elevation of some of the former $M$. flavoviride variants to species level [1]. Kepler and Rehner [6] further specified additional genomic regions for species identification. Molecularly based evaluation of the structure of Metarhizium communities should therefore be included in studies of natural occurrence and distribution to provide full recognition of diversity.

In temperate climatic regions, Metarhizium spp. are predominantly isolated from the soil environment [7]. Surveys of entomopathogenic fungi from soil samples conducted at different geographical locations have shown that $M$. anisopliae s.l. can be abundantly isolated from managed ecosystems [8-15]. However, few studies have evaluated Metarhizium community structure using explicit molecular characterization. In Denmark, Meyling et al. [13] isolated M. anisopliae s.l. from an agricultural field and Steinwender et al. [14] subsequently showed that the Metarhizium community was composed of several species, predominantly M. brunneum followed by $M$. robertsii.

In the soil environment, naturally occurring Metarhizium spp. may also be isolated from roots of different plants $[16,17]$. Some level of plant association was indicated by a predominance of $M$. robertsii found on roots of herbaceous plants as compared to M. brunneum, which was mostly recovered from roots of woody plants [17]. Sampling roots of different plants from an ecosystem might therefore inform about the Metarhizium diversity of an area and reveal potential habitat associations related to plants growing at the site. It was recently shown that similar M. brunneum and $M$. robertsii multilocus genotypes can be repeatedly isolated from roots and soil samples at the same site [18]. However, the structure of the entomopathogenic fungal community in the soil can differ markedly between agricultural fields within relatively close proximity and characterization of a single site may not provide a general distribution pattern. For example, Meyling et al. [13] reported of high frequency of occurrence of $M$. anisopliae s.l. (predominantly $M$. brunneum) at a site in Denmark, while another Danish agricultural field revealed a low occurrence of $M$. anisopliae s.l. [19] using same isolation methods. At the latter site, M. flavoviride was isolated more frequently than M. anisopliae s.l. indicating location specific entomopathogenic fungal communities.

The aim of the current study was to examine the natural occurrence and diversity of Metarhizium spp. isolates obtained from roots and root associated soil of different common crops at geographically separated agricultural fields in Denmark. Fields with oil seed rape, winter wheat as well as permanent grassland were each sampled from three distinct geographical locations. Using such selection criteria, we expected to reveal potential crop and/or location associations of the Metarhizium populations from these three distinct geographical sites. The study resulted in a predominance of $M$. flavoviride isolates which was contrary to our expectations to isolate M. brunneum most frequently based on recent evidence [14]. Metarhizium flavoviride has not previously been studied for withinspecies diversity, thus the intraspecific variability was examined using Amplified Fragment Length Polymorphism (AFLP) markers to evaluate diversity and potential habitat and/or geographical associations.

\section{Results}

\section{Metarhizium distribution and species diversity}

A total of 132 Metarhizium isolates were acquired from the soil samples collected at nine agricultural fields (Table 1). Fourteen of the isolations were obtained using selective media; the remaining 118 isolates were attained using standard soil baiting with Tenebrio molitor larvae. The overall distribution of isolates by area and crop type was not homogenous $\left(\chi^{2}=56.8770 ; \mathrm{df}=4 ; P<0.0001\right)$. A total of 34 isolates were from the Fårevejle area, 71 isolates from Skibby and 27 isolates from Tåstrup; the resulting frequency distribution by area was significantly heterogeneous $\left(\chi^{2}=35.9563 ; \mathrm{df}=2 ; P<0.0001\right)$. Similarly, significantly different frequency distributions were found when compared by crop type $\left(\chi^{2}=12.8636 ; \mathrm{df}=2 ; P=0.0016\right)$.

Of the 132 isolates, 118 were morphologically identified as $M$. flavoviride based on their characteristic bright green colony color and conidial dimensions. The remaining 14 isolates were morphologically classified as belonging to $M$. anisopliae s.l. The $M$. flavoviride isolates were collected from all fields except the uncultivated pasture in Fårevejle (Fig. 1), which had more moist soil than at the other areas.

To verify species identity, 130 of the isolates collected were sequenced for the intergenic region MzFG543igs located between an ATP synthase gamma chain and NAD binding protein encoding genes and phylogenetically analyzed. Species branches of the resulting phylogenetic tree (Fig. 2) were supported by both Bayesian and Maximumlikelihood analyses with 13 isolates clustering with $M$. brunneum. The $M$. brunneum isolates were distributed among three separate clades with two clades represented by isolates from the undeveloped field at Skibby, while eight isolates representing all the three geographical areas clustered with a clade previously found in Denmark (Fig. 2). The $116 \mathrm{M}$. flavoviride isolates that were sequenced for MzFG543igs all shared the same sequence which was similar to isolates from France (Fig. 2). The single isolate of $M$. majus originated from plating of root homogenate on selective agar medium collected at the undeveloped field at Skibby. 
Table 1 Total number of Metarhizium spp. isolations from soil samples collected at three locations in Denmark

\begin{tabular}{|c|c|c|c|c|c|}
\hline Location & Crop & M. brunneum & M. flavoviride & M. majus & Total Metarhizium spp. isolated \\
\hline \multicolumn{6}{|l|}{ Fårevejle } \\
\hline & Oilseed rape & 0 & 17 & 0 & 17 \\
\hline & Winter wheat & 0 & $17(1)$ & 0 & 17 \\
\hline & Grass pasture & 0 & 0 & 0 & 0 \\
\hline \multicolumn{6}{|l|}{ Skibby } \\
\hline & Oilseed rape & 1 & 5 & 0 & 6 \\
\hline & Winter wheat & 2 & $19(1)$ & 0 & 21 \\
\hline & Grass pasture & $6(5)$ & $37(5)$ & $1(1)$ & 44 \\
\hline \multicolumn{6}{|l|}{ Tåstrup } \\
\hline & Oilseed rape & 1 & 1 & 0 & 2 \\
\hline & Winter wheat & 3 & $16(1)$ & 0 & 19 \\
\hline & Grass pasture & 0 & 6 & 0 & 6 \\
\hline Total isolates & & $13(5)$ & $118(8)$ & $1(1)$ & $132(14)$ \\
\hline
\end{tabular}

Each location is represented by three crop types. Three different species were identified and isolates for each are presented and summed. The numbers represent isolates obtained both by insect baiting using Tenebrio molitor larvae and by plating of root homogenate on selective agar media (numbers in brackets represent the isolates obtained on selective media)

\section{Intraspecific variation of $M$. flavoviride}

Amplified fragment length polymorphism (AFLP) analysis was performed using 93 of the $M$. flavoviride isolates collected in this study as well as 13 isolates collected from different geographical locations, including: Jutland, Denmark (Js: $n=9$ ), Årslev, Denmark (Ars: $n=2$ ) [14], Poland (Pol: $n=1$ ), and southern Sweden (Swe: $n=1$ ). The AFLP analysis produced 230 polymorphic loci; however, based on the scoring criteria and inconsistency between dual replicates, only 30 repeatable and consistent loci were selected for inclusion in the analysis. Using the unweighted pair group method with arithmetic mean (UPGMA) analysis, intraspecific variation among the $M$. flavoviride isolates was quite high identifying 78 haplotypes among the 93 analyzed isolates, of which 11 were shared among 2-4 isolates from different areas while the remaining were unique (Fig. 3). However, only three significant AFLP haplotype clusters could be identified by bootstrapping and thus area or crop associated population structure could not be established.

\section{Discussion}

The majority of Metarhizium related research has favored species of the $M$. anisopliae complex; in contrast M. flavoviride are often reported as being infrequently isolated $[8-10,12,16,17,20,21]$ and this species has not been studied in detail. Meyling and Eilenberg [19] have reported significant occurrence of $M$. flavoviride in Denmark within an agroecosystem located close to the fields sampled in Tåstrup in the present study. However, studies at another location in Denmark revealed a predominance of $M$. brunneum isolates using similar isolation methods $[7,14]$. In the present study we surveyed three geographically separate areas and found $M$. flavoviride to be most abundant at all three areas, although at different frequencies of occurrence, indicating that the relatively high frequency of $M$. flavoviride reported by Meyling and Eilenberg [19] was unlikely to be a one-off event. Clearly the species composition of Metarhizium communities is not ubiquitous or random at the studied geographical scales, and further in-depth ecological studies are necessary to identify the driving forces that determine Metarhizium spp. distribution in nature.

The predominance of $M$. flavoviride observed in the present study was unexpected; our initial intention was to analyze the within-species diversity using microsatellites or simple sequence repeat (SSR) markers as done previously [14]; these markers have been shown to be highly suitable for explicit multilocus genotyping [22]. However, the SSR markers developed for M. anisopliae s.l. were observed to have a high frequency ( $>40 \%$ ) of null alleles when tested on $M$. flavoviride isolates and no polymorphism $[14,18]$, and were therefore unsuitable for diversity evaluation within this species. Thus, to characterize the intraspecific variability within $M$. flavoviride and evaluate the diversity we chose to use AFLP markers. Diversity assessment using AFLP markers has been used previously for other Metarhizium spp. isolate collections [10, 23]. Inglis et al. [10] used AFLP markers to determine the diversity within $M$. anisopliae s.l. from western Canada, and they were able to identify several distinct haplotypes. It is important to note however that this was done prior to the Bischoff et al. [5] taxonomic revision and the material evaluated by Inglis et al. [10] has later been split into separate species, predominantly M. brunneum (T. Kabaluk, pers. comm.). Fernandes et al. [23] used AFLP markers to 


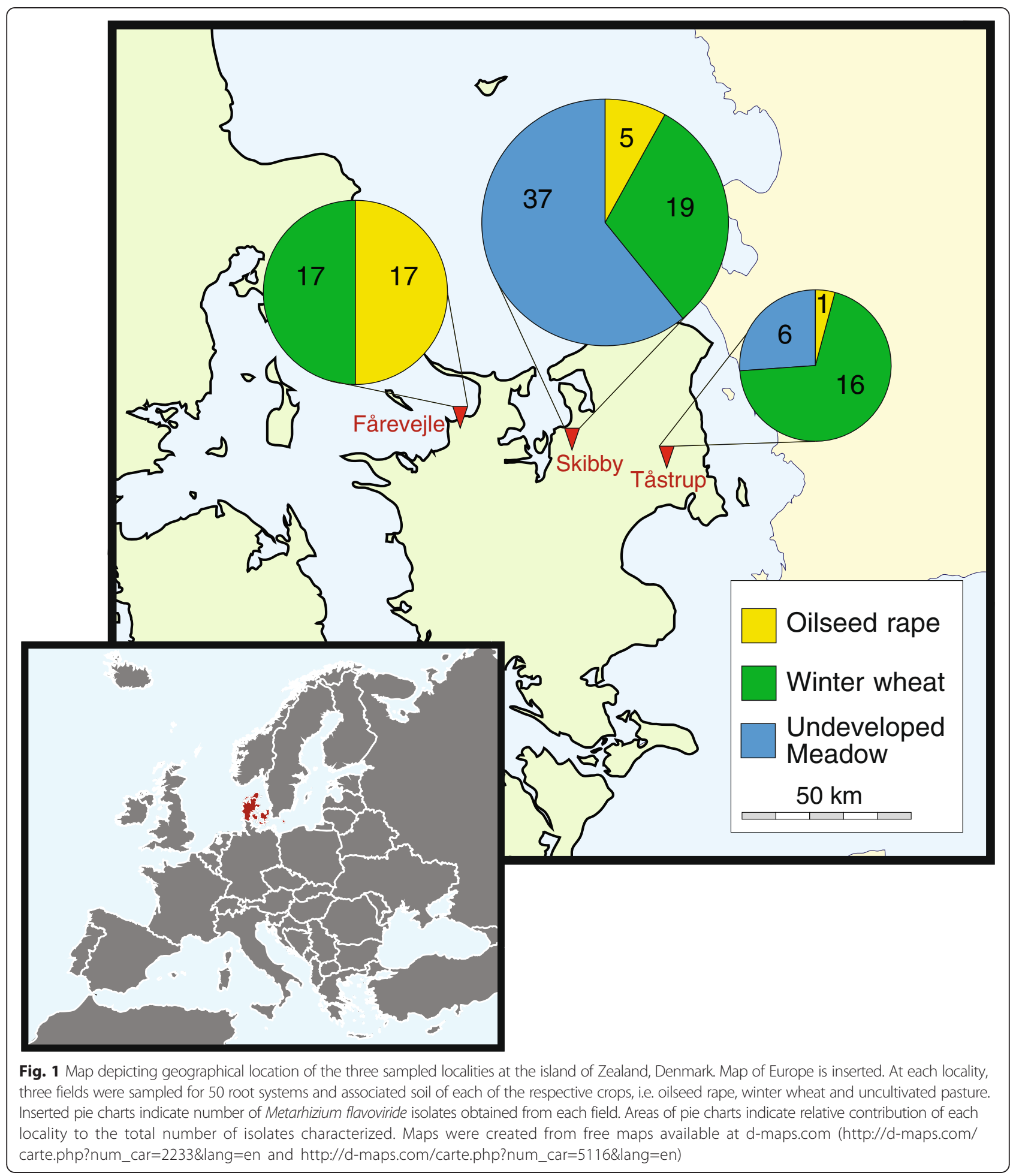

evaluate inter- and intra-species variability among isolates of several Metarhizium species; they found that the method revealed high level of diversity but only clear clustering within $M$. acridum was seen. Reliable species identification placed within an authoritative molecular phylogeny is important when applying general markers such as AFLP to evaluate intra-specific diversity of Metarhizium spp.

In contrast to the relatively few $M$. brunneum isolates sequenced in the current study, all $M$. flavoviride isolates shared the same sequence at the selected genomic intergenic region, even among spatially distant sampled isolates. 


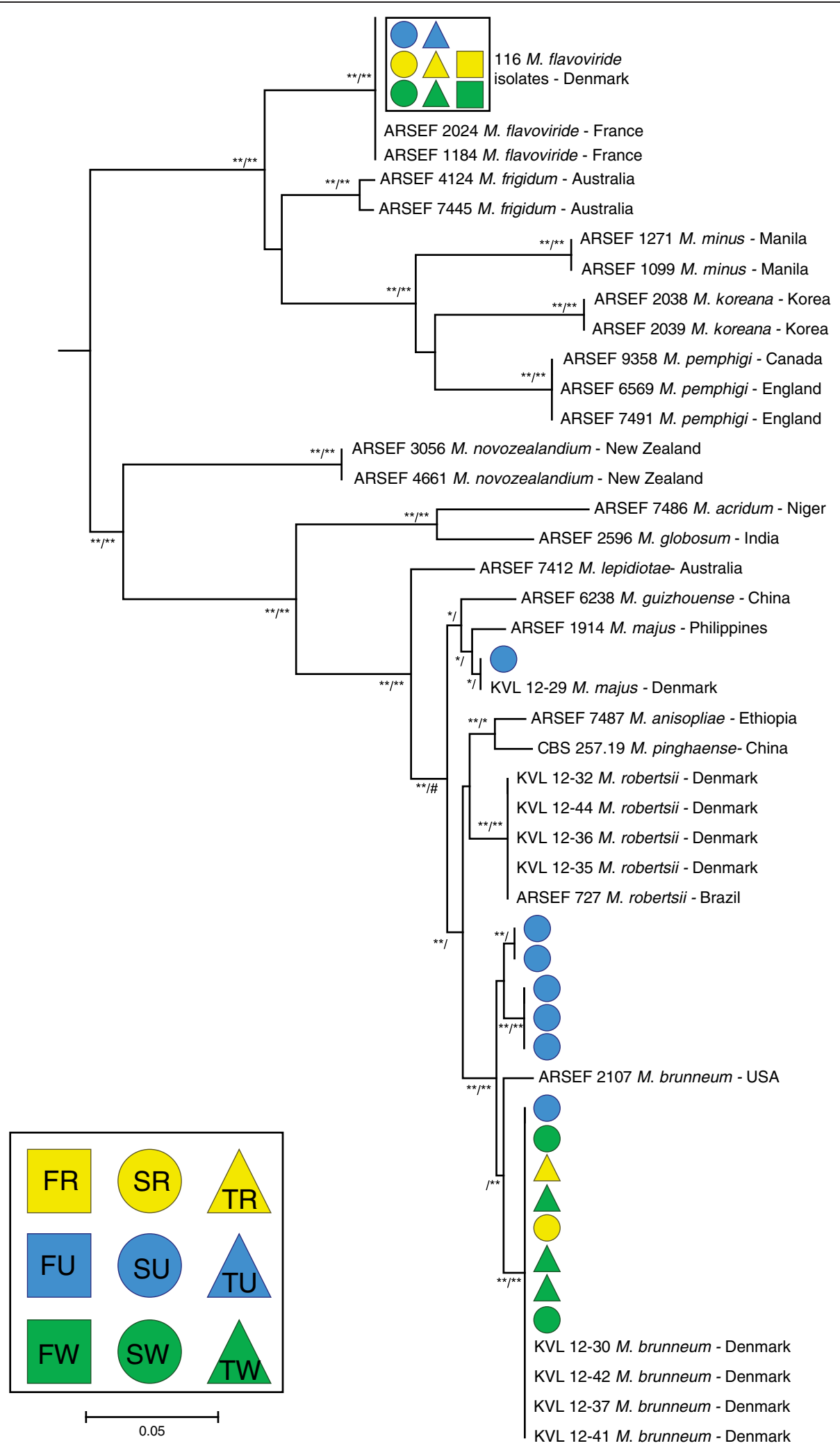

Fig. 2 (See legend on next page.) 
(See figure on previous page.)

Fig. 2 Phylogenetic tree of Metarhizium spp. based on sequence alignment of the nuclear intergenic region MzFG543igs. Tree based on Bayesian analysis is shown with branch support for both Bayesian and Maximum-likelihood analyses; Bayesian $\left(100={ }^{* *}, 95<*\right) /$ Maximum-likelihood $(100$ $=* *, 95<*$; \# denotes where branching topology did not agree between Bayesian and Maximum-likelihood analysis). 130 Metarhizium spp. isolates representing three species were sequences for MzFG543igs. Colored symbols indicate location and crop from which the isolate was acquired [F = Fårevejle (square), $\mathrm{S}=$ Skibby (circle), $\mathrm{T}=$ Tåstrup (triangle), $\mathrm{R}=$ oilseed rape (yellow), $\mathrm{U}=$ un-cultivation pasture (blue), and W = winter wheat (green)]

This indicates that $M$. flavoviride may not be composed of phylogenetically distinct clades as is evident for M. brunneum [14] and M. robertsii [15]. In the present data set $M$. brunneum was also found to be represented by three distinct clades, all co-occurring at the Skibby site. AFLP characterizations of the M. flavoviride isolates included only repeatedly reproduced markers since reproducibility is known to be a challenge with amplified fragments from restriction enzyme markers [22]. The relatively low number of loci in the AFLP analysis is likely to have resulted in the limited statistical support for the haplotype groupings. However, the UPGMA analysis clearly revealed diversity

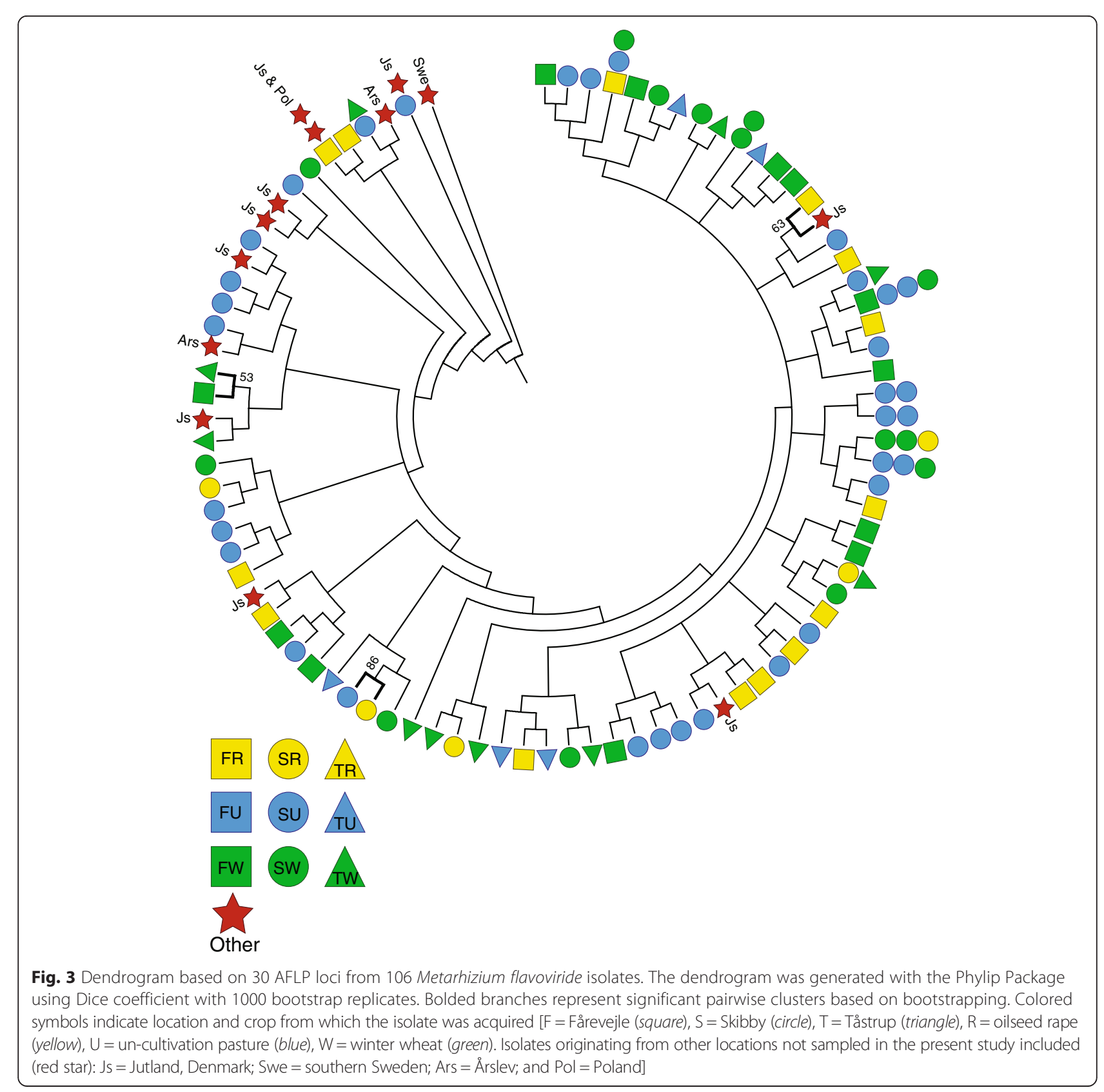


within the species indicating that the isolates are not of the same immediate clonal origin, but also that $M$. flavoviride isolates from other countries shared haplotypes with some of the isolates of the present study. This could tentatively indicate that all the analyzed samples originated from a single diverse population of clonal lineages with little local adaptation. The lack of host specialization and the ability to subsist as a pathogen or saprophyte may result in a reduced rate of adaption, due to limited selection pressure in particular habitats and the advantage of maintaining broad host and habitat ranges. Future development of speciesspecific markers (i.e., microsatellite SSR markers) would however improve the ability to evaluate $M$. flavoviride diversity and determine more evidently any potential habitat associations.

In line with other studies, a single species of Metarhizium was found to be the most prevalent in a given area $[10,14,16,17]$, however it is unclear what factors contribute to this high frequency in the community. Metarhizium spp. are able to acquire nutrients as an insect pathogen or as a plant root associate, which makes it reasonable to suggest that an aptitude at either life strategy would favor a particular species. It has been observed that an isolate of $M$. flavoviride (KVL 14-112) had lower virulence than M. brunneum or M. robertsii isolates towards T. molitor larvae [24] suggesting that M. flavoviride may possess relatively low virulence towards at least some insects. However, Meyling et al. [13] reported of relatively frequent natural mycosis by $M$. flavoviride in aboveground weevils suggesting that the fungus plays a role in the regulation of some insect populations. At the site investigated by Meyling et al. [13] M. brunneum was most frequently isolated by insect baiting of soil samples, but absent as mycosis in aboveground hosts. We implemented two standard methods for the isolation of entomopathogenic fungi in this study, viz., a soil bait method with T. molitor and an in vitro selective media method. Of the two, the soil bait method was most effective in recovering isolates of $M$. flavoviride. The selective media method used was also employed by Wyrebek et al. [17] to isolate Metarhizium spp. from roots of different plants. Although Wyrebek et al. [17] did not report of the isolation of $M$. flavoviride from roots, Behie and Bidochka [25] reported that $M$. flavoviride was able to associate with plant roots in the rhizosphere and transfer nitrogen to the plant from insect cadavers. However, in the present study we sequenced the same isolate (ARSEF 9358) used by Behie and Bidochka [25] which appeared to be M. pemphigi (previously M. flavovoride var. pemphigi), and it thus remains undetermined if $M$. flavoviride can associate with plant roots. The reduced number of isolates of $M$. flavoviride collected on selective media from roots in the present study might indicate that, while present in the soil environment, M. flavoviride was not associating closely with the roots of the crop plants, but neither were other Metarhizium species. Further studies are needed to confirm these observations and investigate what might be driving the $M$. flavoviride predominance at the investigated field sites. However, the current data and that of Meyling et al. [13] indicate that entomopathogenicity is an important ecological trait for $M$. flavoviride occurrence and distribution in agroecosystems.

\section{Conclusion}

The present study revealed that $M$. flavoviride was the predominant Metarhizium species in the soil environment at all three agricultural localities investigated in Denmark each represented by three fields, and that the fungal isolates were mainly obtained using T. molitor baiting. AFLP analysis of the $M$. flavoviride isolates revealed a high level of intra-specific diversity within M. flavoviride, with some widespread AFLP haplotypes also occurring in other countries. This is the first report of an in-depth analysis of the molecular diversity within a large isolate collection of the entomopathogenic fungal species $M$. flavoviride which could lay the foundations for new research of this little investigated fungus.

\section{Methods}

\section{Field sampling}

Three geographically separated areas were located on the island of Zealand, Denmark (Fig. 1), including: Fårevejle $\left(55.78^{\circ} \mathrm{N}, 11.43^{\circ} \mathrm{E}\right)$, Skibby $\left(55.75^{\circ} \mathrm{N}, 11.99^{\circ} \mathrm{E}\right)$ and Tåstrup $\left(55.67^{\circ} \mathrm{N}, 12.3^{\circ} \mathrm{E}\right)$. Within each area three agricultural fields were identified resulting in a 2-level nested design. Each site included one field of winter wheat (Triticum aestivum; var. JB Asano at Fårevejle, var. Jensen at Skibby, var. Tabasco at Tåstrup), one with winter oilseed rape (Brassica napus var. DK-Expower at all sites), and a permanent grass pasture that had been without cultivation for more than 20 years.

From each of the nine fields, 50 root samples were collected by walking an approximately $200 \mathrm{~m}$ transect from the edge of the field towards the center; a combined root/soil sample was collected every 3-4 m using a long-handled weeding fork. Each sample was placed individually in a pre-labeled $10 \mathrm{l}$ polyethylene bag along with $300-500 \mathrm{~g}$ of root-associated soil adhering to the root system. The three fields from each geographic area were sampled on the same day; collections were made on three consecutive days from July 23 to July 25, 2013. After collection samples were placed at $5{ }^{\circ} \mathrm{C}$ until they were processed within 30 days.

\section{Fungal isolation}

Selective media: From each sample a section of the root was removed and washed with $\mathrm{ddH}_{2} \mathrm{O}$ to remove loose 
soil. A portion $(\sim 0.5 \pm 0.25 \mathrm{~g})$ of the washed root was then cut in small pieces $(\sim 2 \mathrm{~mm})$ and placed in $10 \mathrm{ml}$ $\mathrm{ddH}_{2} \mathrm{O}$ and homogenized using a rotary homogenizer [17]. $200 \mu \mathrm{l}$ of homogenate was then spread onto a selective agar media adapted from Fernandes et al. [26], which consisted of: 39 g potato dextrose agar (Sigma Chemical, MO, USA), 1 g yeast extract (Merck KgaA, Darmstadt Germany), 0.25 g cyclohexamide (Sigma Chemical, MO, USA), $0.5 \mathrm{~g}$ chloramphenicol (Sigma Chemical, MO, USA), $0.02 \mathrm{~g}$ dodine (Agriphar, Belgium) (all weights per liter); two plates for each root sample were prepared. After inoculation the plates were incubated for 28 days at $22{ }^{\circ} \mathrm{C}$ in darkness and checked on day 7, 14, 21 and 28. Colonies morphologically identified as Metarhizium were transferred to a clean plate of potato dextrose agar supplemented with $1 \%$ yeast extract (PDAY) using a sterile inoculating needle to obtain pure cultures.

Soil baiting: The soil baiting method used in this study was adapted from Zimmermann [27]. The soil from each sampling site was allowed to air dry over night at room temperature and then re-moistened with $\mathrm{dd}_{2} \mathrm{O}$ so that it was "slightly damp". Soil $(\sim 120 \mathrm{ml})$ was then placed in a plastic cup $(155 \mathrm{ml})$ leaving $1 \mathrm{~cm}$ of airspace at the top. Prior to filling the cup large debris and clumps were removed or broken up. Ten healthy 4-5th instar Tenebrio molitor L. (Coleoptera: Tenebrionidae) larvae were then added to each cup. A lid with ventilation holes was placed on top of each sample and the cups were stacked upside down - so that the larvae were beneath the soil - in a box. Every 1-2 days the box was rotated so that the orientation of the cups shifted, forcing the T. molitor larvae to move through the soil substrate increasing the likelihood they would come in contact with entomopathogens in the soil. Insect survival was checked weekly; dead insects were removed, washed with $\mathrm{ddH}_{2} \mathrm{O}$ and placed in a medicine cup with a moist piece of filter paper to check for mycosis. Using a sterile inoculation needle, fungal isolations were made from insect cadavers with mycosis and plated on PDAY media. After 14 days growth colonies were evaluated, morphologically identified and Metarhizium spp. isolates were kept for further studies.

The frequency distributions of Metarhizium isolates were tested for homogeneity among sampling area and crop type using Pearson's $\chi^{2}$ tests in $\mathrm{R}$ performed in RStudio (version 0.97.551).

\section{PCR amplification and sequencing}

For each Metarhizium isolate, lyophilized mycelium was prepared by growing cultured isolates in liquid media [14] for four days at $22{ }^{\circ} \mathrm{C}$ on a stirring table at $170 \mathrm{rpm}$. Mycelium was separated using a vacuum filtration system, frozen over night at $-20{ }^{\circ} \mathrm{C}$ and lyophilized. DNA was extracted from the lyophilized mycelia using the DNeasy Plant Mini Kit (QIAGEN, Hilden, Germany) following the manufacturer's instructions.

The PCR amplification and sequencing methods in this study were of the intergenic region MzFG543igs region flanked by the coding regions of the genes ATP synthase gamma chain and NAD binding protein according to Kepler and Rehner [6]. The master mix reagents for each PCR reaction consisted of: $32 \mu \mathrm{l}$ milliQ $\mathrm{H}_{2} \mathrm{O}, 5 \mu \mathrm{l}$ Taq DNA buffer, $1 \mu \mathrm{dNTP}, 1 \mu \mathrm{l}$ Taq DNA polymerase, $5 \mu \mathrm{l}$ of each primer, and $1 \mu \mathrm{DNA}$ sample. The primers used were MzFG543igs_1F (5'-ATT CAT TCA GAA CGC CTC CAA-3') and MzFG543igs_4R (5'-GGT TGC GAC TCA CAA TCC ATG-3'). PCR amplification was initiated by denaturation at $95^{\circ} \mathrm{C}$ for 2 min followed by 40 cycles of three steps including: $95{ }^{\circ} \mathrm{C}$ denaturation for $30 \mathrm{~s}, 62{ }^{\circ} \mathrm{C}$ annealing for $30 \mathrm{~s}$, and $72{ }^{\circ} \mathrm{C}$ extension for $60 \mathrm{~s}$; after the 40 cycles the final step was $72{ }^{\circ} \mathrm{C}$ extension for $15 \mathrm{~min}$. The PCR products were visualized on $1.5 \%$ agarose gel to ensure strong single bands and purified using the Illustra ${ }^{\mathrm{Tm}}$ GFX $^{\mathrm{Tw}}$ PCR DNA and Gel Band Purification Kit. The purified PCR products were sent to Beckman Coulter Genomics (UK) for sequencing with the PCR primers. The sequence chromatograms were manually corrected and aligned using ClustalW [28] with default settings as implemented in BioEdit 7.1.3 [29]. Additionally, sequences of known Metarhizium spp. isolates from Kepler et al. [1] in addition to three Metarhizium spp. isolates from the ARSEF collection (i.e., ARSEF nos. 1184, 1271 and 9358) were included in the phylogenetic analyses. Sequences are deposited in GenBank (Table 2). The $\sim 900$ base pair multiple alignment was analyzed using ModelTest to determine the optimal DNA substitution model and evaluated with AIC scores as

Table 2 List of selected Metarhizium spp. isolates from Denmark characterized in the present study

\begin{tabular}{lllll}
\hline Species & Isolate accession & Isolate origin & GenBank accession & References \\
\hline Metarhizium flavoviride & KVL 14-112 & Undeveloped pasture, T. molitor bait larva, Skibby & KT335973 & This study; [24] \\
M. majus & KVL 14-21 & Undeveloped pasture, SM, Skibby & KT335974 & This study \\
M. robertsii & KVL 12-32 & Organic field, T. molitor bait larva, Årslev & KT335975 & This study; [14] \\
M. brunneum & KVL 14-08 & Undeveloped pasture, SM, Skibby & KT335976 & This study \\
M. brunneum & KVL 14-10 & Undeveloped pasture, SM, Skibby & KT335977 & This study \\
M. brunneum & KVL 14-40 & Wheat, T. molitor bait larva, Skibby & KT335978 & This study \\
\hline
\end{tabular}

Isolates were obtained by in vitro culturing on selective agar media (SM) or by bating soil samples with mealworm larvae (T. molitor) 
implemented in Topali [30]. The phylogeny was inferred with maximum likelihood estimation using RaxML with 500 bootstrap replicates and Bayesian analyses using MrBayes ver3.1 and executed from within Topali. The final dendrogram was depicted suing MEGA5 [31].

\section{Intraspecific variation of $M$. flavoviride}

New DNA extractions with a greater quantity of DNA were made from the lyophilized mycelium. This was accomplished using the Qiagen DNeasy Plant Mini Kit with the following protocol modifications: A small amount of lyophilized material ( 2-3 "match-head" size pieces) was placed in a $2 \mathrm{ml}$ Eppendorf vial, which had been prepared with $1.0 \mathrm{~mm}$ and $2.5 \mathrm{~mm}$ dia. zirconiaglass beads (Biospec Products). Next, $600 \mu \mathrm{l}$ buffer AP1 from the Qiagen DNeasy Plant Mini Kit (cat. no. 69104) was added and the samples homogenized in a FastPrep machine (BIO101/Savant FP120 FastPrep, Qbiogene, CA, USA) and shaken twice for $35 \mathrm{~s}$ at 5.0 speed. The samples were then removed and $6 \mu$ l of proteinase $K$ and $6 \mu \mathrm{l}$ RNase A from the Qiagen DNeasy Plant Mini Kit were added and incubated at $65{ }^{\circ} \mathrm{C}$ for $1 \mathrm{~h}$ during which they were manually shaken every 15 min. After incubation, $195 \mu \mathrm{l}$ buffer P3 was added and they were incubated on ice for $5 \mathrm{~min}$. The remaining steps were according to the protocol and the DNA was eluted in $50 \mu \mathrm{l}$ buffer AE. The quantity and quality of DNA available in the extracted material was quantified using a NanoDrop 1000 (Thermo Scientific).

The Amplified Fragment Length Polymorphism (AFLP) procedures were performed according to Vos et al. [32], and the amount of DNA per reaction were standardized to $100 \pm 20 \mathrm{ng}$. Initially the DNA was digested by two restriction enzymes (EcoRI and MseI) and oligonucleotide adapters attached to the resulting ends. This was accomplished by preparing two master mixes, master mix A contained: $0.1 \mu \mathrm{l} \mathrm{MseI}(10 \mathrm{u} / \mu \mathrm{l}), 0.25 \mu \mathrm{l}$ Eco RI $(20 \mathrm{u} / \mu \mathrm{l})$, $0.1 \mu \mathrm{l}$ T4 ligase $(6 \mathrm{Weiss} \mathrm{u} / \mu \mathrm{l}), 0.1 \mu \mathrm{l}$ T4 ligase buffer, $0.05 \mu \mathrm{l}$ diluted $(1 \mathrm{mg} / \mathrm{ml})$ BSA, $0.1 \mu \mathrm{l} 0.5 \mathrm{M} \mathrm{NaCl}$, and $0.3 \mu \mathrm{l}$ milliQ $\mathrm{H}_{2} \mathrm{O}$, for each reaction. Master mix B contained: $1 \mu \mathrm{l} 10 \times \mathrm{T} 4$ ligase buffer, $1 \mu \mathrm{l} 0.5 \mathrm{M} \mathrm{NaCl}, 0.5 \mu \mathrm{l}$ diluted BSA ( $1 \mathrm{mg} / \mathrm{ml}), 1 \mu \mathrm{l}$ MseI adaptor pair, $1 \mu \mathrm{l} \mathrm{EcoRI}$ adaptor pair, for each reaction. Prior to preparing master mix B, the MseI and EcoRI adaptor pairs were heated to $95{ }^{\circ} \mathrm{C}$ for $5 \mathrm{~min}$ and then allowed to cool at room temperature for $10 \mathrm{~min}$; the MseI adaptor pair consisted of a 1:1 combination of M-ADAP I (5'-GAC GAT GAG TCC TGA G-'3) and M-ADAP II (5'-TAC TCA GGA CTC AT-'3) and the EcoRI adaptor pair consisted of a 1:1 combination of E-ADAP I (5' -CTC GTA GAC TGC GTA CC-'3) and E-ADAP II (3'-CAT CTG ACG CAT GGT TAA-'5) at a concentration of $20 \mu \mathrm{M}$ each (so after combination the concentration of each is $10 \mu \mathrm{M}$ ). After preparation master mix $\mathrm{B}$ was added to master mix $\mathrm{A}$ and mixed before $5.5 \mu \mathrm{l}$ of DNA was added so that the total volume was $11 \mu \mathrm{l}$. This was then incubated at $37^{\circ} \mathrm{C}$ for $2 \mathrm{~h}$, after which $189 \mu \mathrm{l}$ of milliQ $\mathrm{H}_{2} \mathrm{O}$ was added.

A PCR preamplification of the restriction-ligation products consisted of: $12.55 \mu \mathrm{l}$ milliQ $\mathrm{H}_{2} \mathrm{O}, 4 \mu \mathrm{l}$ Phusion buffer (Finnzymes), $0.4 \mu \mathrm{l}$ dNTP $(10 \mu \mathrm{M}), 0.25 \mu$ l Phusion polymerase (Finnzymes), $0.4 \mu \mathrm{l}$ Eco pre-amp primer (5'-GAC TGC GTA CCA ATT CA-'3), and 0.4 $\mu$ l Mse pre-amp primer (5'-GAT GAG TCC TGA GTA AC-'3). To this mixture $2 \mu \mathrm{l}$ of the product from the cut ligation above was added. The DNA fragments were then amplified using the following PCR program: $98{ }^{\circ} \mathrm{C}$ denaturation for $30 \mathrm{~s}$, followed by 35 cycles next three steps, $98{ }^{\circ} \mathrm{C}$ denaturation for $30 \mathrm{~s}, 56{ }^{\circ} \mathrm{C}$ annealing for $30 \mathrm{~s}$, and $72{ }^{\circ} \mathrm{C}$ extension for $1 \mathrm{~min}$; after the 35 cycles the final step was $72{ }^{\circ} \mathrm{C}$ extension for $120 \mathrm{~s}$. A 1:10 dilution of the preamp product was then made and used in the selective amplification step.

A selective amplification mixture was prepared which consisted of: $11.85 \mu \mathrm{l}$ milliQ $\mathrm{H}_{2} \mathrm{O}, 4 \mu \mathrm{l}$ Phusion buffer, $0.4 \mu \mathrm{l}$ dNTP $(10 \mu \mathrm{M}), 0.25 \mu \mathrm{l}$ Phusion polymerase, $1 \mu \mathrm{l}$ Eco sel-amp primer with FAM labeled $(10 \mu \mathrm{M})\left(5^{\prime}\right.$-GAC TGC GTA CCA ATT CAC C-'3), $0.5 \mu$ l Mse sel-amp CAC primer $(20 \mu \mathrm{M})\left(5^{\prime}\right.$-GAT GAG TCC TGA GTA ACA C-'3), and $0.5 \mu \mathrm{l}$ Mse sel-amp CAT primer $(20 \mu \mathrm{M})$ (5'-GAT GAG TCC TGA GTA ACA T-'3). To this $1.5 \mu \mathrm{l}$ of the diluted pre-amplification product was added to bring the total volume to $20 \mu \mathrm{l}$. The following PCR program was performed: for 8 cycles, $98^{\circ} \mathrm{C}$ denaturation for $30 \mathrm{~s}, 65^{\circ} \mathrm{C}$ annealing for $30 \mathrm{~s}$, and $72{ }^{\circ} \mathrm{C}$ extension for $90 \mathrm{~s}$, reducing the annealing temperature $1{ }^{\circ} \mathrm{C}$ each cycle; then 24 cycles of: $98{ }^{\circ} \mathrm{C}$ denaturation for $30 \mathrm{~s}, 56{ }^{\circ} \mathrm{C}$ annealing for $30 \mathrm{~s}$, and $72{ }^{\circ} \mathrm{C}$ extension for $90 \mathrm{~s}$, followed by $72{ }^{\circ} \mathrm{C}$ for $7 \mathrm{~min}$. This was then visualized on $1.5 \%$ agarose gel to insure the presence of a distinct smear and banding pattern.

The selective amplification products were prepared for fragment length analysis by mixing: $0.1 \mu \mathrm{l}$ sample in $8.7 \mu \mathrm{l}$ formamide and $0.3 \mu \mathrm{l}$ Genescan Rox500 (Applied Biosystems). The samples were then analyzed on ABI Prism 3100 Genetic Analyzer (Applied Biosystems, Foster City, CA). The entire AFLP procedure was performed twice using the same extracted DNA resulting in two technical replicates for each isolate. Because the samples were run on more than one 96-well plate, a specific isolate was included on all plates to control for plate-specific variation. Presence of bands were scored as follows using GeneMapper software 5 (Applied Biosystems) and ROX500 as internal size standard: AFLP fragments were scored as present (1) if they had a signal intensity greater than 100 in duplicate samples, or if there was a disagreement between the two replicates and one was above 100 and the other was above 50. In contrast, if an AFLP fragment had signal intensity less than 100 for both isolate replicates or if one was below 50 then it was considered absent (0). A signal intensity 
of 50 was considered the absolute minimum to be reliably scored and distinguished from background noise. A cluster analysis of the resulting binomial data set was performed by calculating the pairwise distance measure using Dice coefficient with 1000 bootstrap replicates using DistAFLP (available at: http://pbil.univ-lyon1.fr/ ADE-4/microb/) [33]. These bootstrap trees were then analyzed using the Neighbor and Consensus executables in the Phylip Package [34] to produce a tree with bootstrap support based on the unrooted unweighted pair group method with arithmetic mean (UPGMA) [35].

\section{Availability of supporting data}

Representative DNA sequences obtained in the present study were deposited in GenBank, National Center for Biotechnology Information (NCBI) under accession numbers KT335973-KT335978 (http://www.ncbi.nlm.nih.gov/). The AFLP scoring matrix used for the UPGMA analysis in Fig. 3 is available as Additional file 1.

\section{Additional file}

Additional file 1: Fragment scoring matrix (presence $=1$, light green; absence $=0$ ) of Amplified Fragment Length Polymorphism (AFLP) data. Only fragments positive in duplicate runs were scored as present. Results of analysis of AFLP data are presented in Fig. 3. (XLSX 21 kb)

\begin{abstract}
Abbreviations
AFLP: amplified fragment length polymorphism; AIC: akaike information criterion; ARSEF: The USDA-ARS collection of entomopathogenic fungal cultures; NAD: nicotinamide adenine dinucleotide; PDAY: potato dextrose agar supplemented with $1 \%$ yeast extract; UPGMA: unweighted pair group method with arithmetic mean; SSR: simple sequence repeats.
\end{abstract}

\section{Competing interests}

The authors declare that they have no competing interests.

\section{Authors' contributions}

CAK and NVM conceived the study, designed the sampling plan and carried out the field sampling; CAK and BMS isolated the fungi, extracted DNA and performed sequencing; CAK and HHDFL analyzed the sequence data set, performed and analyzed the AFLP data set; all authors wrote the manuscript and have approved the final version.

\begin{abstract}
Acknowledgements
We would like to give special thanks to Line Lykke, Lærke Thordsen, Azmi Mahmood, Darren Thomsen, Jesper Andersen, Sylvia Mathiasen and Louise Lee Munk Larsen for their technical assistance during several phases of this study. We would also like to thank the farmers at each location for allowing us to sample their fields. This research was funded by a PhD grant to CAK from the Plant Biosystems Elite Environment at the University of Copenhagen. HHDFL was supported by the Carlsberg Foundation.
\end{abstract}

Received: 6 May 2015 Accepted: 23 October 2015

Published online: 30 October 2015

\section{References}

1. Kepler RM, Humber RA, Bischoff JF, Rehner SA. Clarification of generic and species boundaries for Metarhizium and related fungi through multigene phylogenetics. Mycologia. 2014;106:811-29.

2. Roberts DW, St. Leger RJ. Metarhizium spp., cosmopolitan insect-pathogenic fungi: Mycological aspects. Adv Appl Microbiol. 2004;54:1-70.
3. Zimmermann G. Review on safety of the entomopathogenic fungus Metarhizium anisopliae. Biocontrol Sci Tech. 2007;17:879-920.

4. Meyling NV, Eilenberg J. Ecology of the entomopathogenic fungi Beauveria bassiana and Metarhizium anisopliae in temperate agroecosystems: Potential for conservation biological control. Biol Control. 2007:43:145-55.

5. Bischoff JF, Rehner SA, Humber RA. A multilocus phylogeny of the Metarhizium anisopliae lineage. Mycologia. 2009;101:512-30.

6. Kepler RM, Rehner SA. Genome-assisted development of nuclear intergenic sequence markers for entomopathogenic fungi of the Metarhizium anisopliae species complex. Mol Ecol Resour. 2013;13:210-7.

7. Vega FE, Meyling NV, Luangsa-ard JJ, Blackwell M. Fungal entomopathogens. In: Kaya H, Vega FE, editors. Insect pathology. 2nd ed. San Diego: Academic; 2012. p. 171-220.

8. Bidochka MJ, Kasperski JE, Wild GAM. Occurrence of the entomopathogenic fungi Metarhizium anisopliae and Beauveria bassiana in soils from temperate and near-northern habitats. Can J Bot. 1998;76:1198-204.

9. Goble TA, Dames JF, Hill MP, Moore SD. The effects of farming system, habitat type and bait type on the isolation of entomopathogenic fungi from citrus soils in the Eastern Cape Province, South Africa. BioControl. 2010;55:399-412.

10. Inglis GD, Duke GM, Goettel MS, Kabaluk JT. Genetic diversity of Metarhizium anisopliae var. anisopliae in southwestern British Columbia. J Invertebr Pathol. 2008:98:101-13.

11. Klingen I, Eilenberg J, Meadow R. Effects of farming system, field margins and bait insect on the occurrence of insect pathogenic fungi in soils. Agr Ecosyst Environ. 2002;91:191-8.

12. Sun B-D, Yu H-y, Chen AJ, Liu X-Z. Insect-associated fungi in soils of field crops and orchards. Crop Prot. 2008;27:1421-6.

13. Meyling NV, Thorup-Kristensen K, Eilenberg J. Below- and aboveground abundance and distribution of fungal entomopathogens in experimental conventional and organic cropping systems. Biol Control. 2011;59:180-6.

14. Steinwender BM, Enkerli J, Widmer F, Eilenberg J, Thorup-Kristensen K, Meyling NV. Molecular diversity of the entomopathogenic fungal Metarhizium community within an agroecosystem. J Invertebr Pathol. 2014;123:6-12.

15. Kepler RM, Ugine TA, Maul JE, Cavigelli MA, Rehner SA. Community composition and population genetics of insect pathogenic fungi in the genus Metarhizium from soils of a long-term agricultural research system. Environ Microbiol. 2015;17:2791-2804 doi:10.1111/1462-2920.12778.

16. Fisher JJ, Rehner SA, Bruck DJ. Diversity of rhizosphere associated entomopathogenic fungi of perennial herbs, shrubs and coniferous trees. J Invertebr Pathol. 2011;106:289-95.

17. Wyrebek M, Huber C, Sasan RK, Bidochka MJ. Three sympatrically occurring species of Metarhizium show plant rhizosphere specificity. Microbiol. 2011;157:2904-11.

18. Steinwender BM. Entomopathogenic fungi Metarhzium spp. in the soil environment of an agroecosystem: molecular diversity, root association and ecological characteristics. PhD Thesis, University of Copenhagen; 2013.

19. Meyling NV, Eilenberg J. Occurrence and distribution of soil borne entomopathogenic fungi within a single organic agroecosystem. Agr Ecosyst Environ. 2006;113:336-41.

20. Quesada-Moraga E, Navas-Cortés JA, Maranhao EAA, Ortiz-Urquiza A, Santiago-Álvarez C. Factors affecting the occurrence and distribution of entomopathogenic fungi in natural and cultivated soils. Mycol Res. 2007;111:947-66

21. Vanninen I. Distribution and occurrence of four entomopathogenic fungi in Finland: Effect of geographical location, habitat type and soil type. Mycol Res. 1995;100:93-101.

22. Enkerli J, Widmer F. Molecular ecology of fungal entomopathogens: molecular genetic tools and their applications in population and fate studies. BioControl. 2010;55:17-37.

23. Fernandes EK, Keyser CA, Chong JP, Rangel D, Miller MP, Roberts DW. Characterization of Metarhizium species and varieties based on molecular analysis, heat tolerance and cold activity. J Appl Microbiol. 2010;108:115-28.

24. Keyser CA, Jensen B, Meyling NV. Dual effects of Metarhizium spp. and Clonostachys rosea against an insect and a seed borne pathogen in wheat. Pest Manag Sci. 2015. doi:10.1002/ps.4015.

25. Behie SW, Bidochka MJ. Ubiquity of insect-derived nitrogen transfer to plants by endophytic insect-pathogenic fungi: an additional branch of the soil nitrogen cycle. Appl Environ Microbiol. 2014;80:1553-60.

26. Fernandes EK, Keyser CA, Rangel DEN, Foster RN, Roberts DW. CTC medium: A novel dodine-free selective medium for isolating entomopathogenic fungi, especially Metarhizium acridum, from soil. Biol Control. 2010;54:197-205. 
27. Zimmermann G. The 'Galleria bait method' for detection of entomopathogenic fungi in soil. J Appl Entomol. 1986;102:213-5.

28. Larkin MA, Brown NP, Chenna R, McGettigan PA, McWilliam H, Valentin F, et al. ClustalW and ClustalX version 2. Bioinformatics. 2007;23:2947-8

29. Hall TA. BioEdit: a user-friendly biological sequence alignment editor and analysis program for Windows 95/98/NT. Nucleic Acids Symp Ser. 1999;41:95-8.

30. Milne I, Lindner D, Bayer M, Husmeier D, McGuire G, Marshall DF, et al. TOPALi v2: a rich graphical interface for evolutionary analyses of multiple alignments on HPC clusters and multi-core desktops. Bioinformatics. 2009;25:126-7

31. Tamura K, Peterson D, Peterson N, Stecher G, Nei M, Kumar S. MEGA5: molecular evolutionary genetics analysis using maximum likelihood, evolutionary distance, and maximum parsimony methods. Mol Biol Evol. 2011;28:2731-9.

32. Vos P, Hogers R, Bleeker M, Reijans M, Vandelee T, Hornes M, et al. AFLP new technique for DNA-fingerprinting. Nucleic Acids Res. 1995;23:4407-14.

33. Mougel C, Thioulouse J, Perriere G, Nesme X. A mathematical method for determining genome divergence and species delineation using AFLP. Int J Syst Evol Microbiol. 2002:52:573-86.

34. Felsenstein J. PHYLIP (Phylogeny Inference Package) version 3.6. Seattle: Distributed by the author Department of Genome Sciences, University of Washington; 2005

35. Sneath PHA, Sokal RR. Numerical taxonomy. The principles and practice of numerical classification. San Francisco: W. H. Freeman; 1973.

\section{Submit your next manuscript to BioMed Central and take full advantage of:}

- Convenient online submission

- Thorough peer review

- No space constraints or color figure charges

- Immediate publication on acceptance

- Inclusion in PubMed, CAS, Scopus and Google Scholar

- Research which is freely available for redistribution 